\title{
POR UMA ABORDAGEM ESPACIAL NA GESTÃO DE POLÍTICAS EDUCACIONAIS: EQUIDADE PARA SUPERAR DESIGUALDADES
}

\author{
SANDRA GOMES ${ }^{1}$ \\ Francymonni Yasmim Marques de Melo²
}

\begin{abstract}
RESUMO: Estudos sobre as relações entre desempenho escolar, características individuais e local de moradia concluem que a sobreposição de diferentes tipos de desvantagens para indivíduos em situação de vulnerabilidade social são os principais fatores explicativos para a baixa performance escolar. A partir de indicadores educacionais intraurbanos, os autores identificam padrões de desigualdades socioespaciais associados a uma distribuição desigual de infraestrutura pedagógica das escolas, explicados pela constituição histórica de ocupação do espaço urbano e reiterados pelas escolhas de políticas públicas. Ao fim, argumenta-se que um olhar espacial para planejamento e gestão das políticas educacionais pode se tornar um efetivo instrumento para correção das desigualdades e promoção da equidade.
\end{abstract}

Palavras-chave: Gestão de políticas educacionais. Desigualdades socioespaciais. Equidade. Segregação urbana. Desempenho escolar.

\section{A SPATIAL APPROACH FOR EDUCATION POLICIES: EQUITY TO OVERCOME INEQUALITIES}

\begin{abstract}
Studies on school performance, individual characteristics, and place of residence conclude that the overlapping of different types of individual disadvantages in situations of social vulnerability are the main explanatory factors for low school performance. Based on intra-urban educational indicators, the authors identify patterns of socio-spatial inequalities associated with an unequal distribution of pedagogical infrastructure among schools, explained by the historical constitution of urban occupation, and reiterated by the choices of public policies. Finally, it is argued that a spatial approach to planning and management of educational policies can become an effective instrument for correcting inequalities and promoting equity.
\end{abstract}

Keywords: Educational policies. Socio-spatial inequalities. Equity. Urban segregation. School performance.

Uma versão preliminar deste texto foi apresentada no XVIII ENANPUR. Apoio institucional foi gentilmente garantido pelo Programa de Pós-Graduação em Estudos Urbanos e Regionais e pela Pró-Reitoria de Pós-Graduação da UFRN, além da CAPES.

1.Universidade Federal do Rio Grande do Norte -Departamento de Políticas Públicas - Programa de Pós-graduação em Estudos Urbanos e Regionais- Natal (RN), Brasil. E-mail: sgomes.vaughan@gmail.com

2.Universidade Federal do Rio Grande do Norte - Programa de Pós-graduação em Estudos Urbanos e Regionais - Natal (RN), Brasil. E-mail: francymonni@gmail.com

Editor de Seção: Salomão Barros Ximenes 


\title{
PARA UN ENFOQUE ESPACIAL EN LA GESTIÓN DE LA POLÍTICA EDUCATIVA: EQUIDAD PARA SUPERAR LAS DESIGUALDADES
}

\begin{abstract}
RESUMEN: Los estudios sobre las relaciones entre el rendimiento escolar, las características individuales y el lugar de residencia concluyen que la superposición de diferentes tipos de desventajas para las personas en situaciones de vulnerabilidad social son los principales factores explicativos para el bajo rendimiento escolar. Sobre la base de indicadores educativos intraurbanos, los autores identifican patrones de desigualdades socioespaciales asociados con una distribución desigual de la infraestructura pedagógica de las escuelas, explicada por la constitución histórica de la ocupación del espacio urbano y reiterada por las opciones de políticas públicas. Por fin, se argumenta que una visión espacial para la planificación y gestión de las políticas educativas puede convertirse en un instrumento eficaz para corregir las desigualdades y promover la equidad.
\end{abstract}

Palabras-clave: Gestión de políticas educativas. Desigualdades socioespaciales. Equidad Segregación urbana. Rendimento escolar.

\section{Introdução}

A

educação é entendida tanto como um meio de superação da condição de pobreza e das desigualdades (DUBET et al., 2012) quanto como reprodutora das hierarquias sociais existentes (BOURDIEU; PASSERON, 1982). Ainda que a educação seja um típico fenômeno social complexo (RAGIN, 1987), isto é, com uma miríade de fatores explicativos e combinações causais, este artigo foca em um debate específico: os efeitos da educação nas oportunidades sociais dos indivíduos dependem do tipo de escola a que eles têm acesso. A sobreposição de desvantagens sociais em espaços segregados e de alta vulnerabilidade social, como é o caso das periferias das cidades brasileiras, tende a reproduzir as desigualdades de origem. Estudos apontam que esses locais acabam por acumular uma série de obstáculos recorrentes aos indivíduos, como menor oportunidade de emprego (GOMES; AMITRANO, 2005); rede de relações sociais menos diversificada (MARQUES, 2010); condições habitacionais e urbanas mais precárias (RIBEIRO et al., 2016), entre outros aspectos que, em conjunto, tornam as chances de superação das condições de pobreza e de vulnerabilidade mais difíceis. De modo similar, estudos sobre a relação entre desempenho escolar e espaço chegam a consistentes achados que mostram piores condições escolares nas regiões periféricas das cidades e metrópoles brasileiras (RIBEIRO et al., 2016; TORRES et al., 2005), compreendidas "como um dos elementos fundantes do processo de formação territorial brasileiro" (GIROTTO; CÁSSIO, 2018, p. 3).

Ainda que esses estudos apontem que os efeitos da segregação no desempenho e nas oportunidades educacionais sejam menores que os fatores considerados tradicionalmente pela literatura (ALVES; SOARES, 2013), como as características individuais, esses se sobrepõem, aumentando as chances de reprodução ou manutenção das desigualdades sociais. Nesse sentido, o princípio igualitário e isonômico que norteia a gestão educacional brasileira parece ser insuficiente para a superação das desigualdades de renda, raça, gênero ou status social, na medida em que são justamente os locais mais periféricos os que mais se beneficiariam do acesso a uma educação de qualidade.

Torres et al. (2008), por exemplo, argumentam que regras universais e objetivas adotadas de modo cotidiano na gestão da política educacional acabam por produzir resultados adversos para as escolas periféricas, como profissionais menos qualificados ou menor infraestrutura pedagógica, entre outros. 
Iniciativas que priorizam o atendimento de alunos beneficiários do Bolsa-Família, por exemplo, encontram resistência na comunidade de gestores e especialistas da educação, orientados por um sistema de crenças bastante consolidado e baseado em regras universais e igualitárias, que exclui a possibilidade de adoção de princípios equalizadores - isto é, de tratamento diferenciado para os desiguais.

Argumentamos aqui que o balanço dessa literatura mostra que um olhar espacial no processo de tomada de decisão pela gestão pública pode ensejar a adoção de mecanismos corretores das desigualdades educacionais na perspectiva da equidade; ou seja, que minimizem as desigualdades sociais de origem. A isso se associam também as transformações na política educacional brasileira no período democrático, que tornaram a gestão de políticas educacionais a cargo de estados e municípios mais complexa (MENICUCCI; GOMES, 2018; GOMES et al., 2019). Tendo em vista a centralidade do papel de estados e municípios como os provedores majoritários da educação básica no Brasil, a capacidade de planejamento e de gestão desses entes sobre a política educacional é um fator estratégico para ações que intencionem romper com os mecanismos que persistem em reproduzir as desigualdades sociais de origem.

Defendemos também que um dos instrumentos de gestão disponíveis para esse fim é a análise da distribuição espacial das condições educacionais como forma de identificar os locais que acumulam desvantagens individuais e espaciais. Entendida a política pública de educação como conjunto de instrumentos de planejamento e gestão que estão à disposição de governos estaduais e municipais - principais provedores da educação básica no Brasil -, partimos do pressuposto de que há ferramentas de ação para embasar as autoridades responsáveis pela tomada de decisões que tenham como foco a diminuição das desigualdades educacionais. A análise dos dados empíricos aqui apresentados mostra que condições escolares ainda são desigualmente distribuídas, mesmo no interior de uma mesma rede de ensino. Mais do que isso, princípios equalizadores, priorizando justamente as escolas em regiões de maior vulnerabilidade social, de fato, não parecem orientar a gestão pública educacional. Discutimos essa estratégia analítica e de instrumento de gestão com foco em cidades, mas os mesmos princípios podem ser aplicados a outros espaços, urbanos e rurais.

O texto está organizado da maneira que se segue. Na primeira seção, com base em estudos internacionais e do caso brasileiro, levantamos alguns dos argumentos sobre o papel da escola na superação das condições de desigualdades e como a sobreposição de desvantagens em espaços segregados contribui para a reprodução das dessas desigualdades. Adotamos, aqui, o termo "espaço", não "território" - como no conceito da Geografia -, pois nossa discussão não tem a pretensão de analisar de modo sistemático a constituição de territórios, como discutido em Santos e Silveira (2006). Nossos objetivos são mais modestos e pragmáticos: como a gestão pública pode adotar instrumentos de correção de desigualdades educacionais a partir de um olhar que leve em consideração o espaço e seus constituintes e que, ainda que não altere a dinâmica de formação territorial, possa compensar, ao menos parcialmente, as desigualdades sociais de origem.

Na segunda seção, apresentamos um caso empírico para fundamentar o argumento de que um olhar espacial e equalizador poderia ser adotado para embasar o planejamento e a tomada de decisão pela gestão pública. Para isso, utilizamos dados educacionais das redes de ensino municipal e estadual do município de Natal, apresentando-os por bairros e regiões administrativas e aplicando o princípio equalizador e espacial como instrumento de gestão. A aplicação revela uma diversidade de situações em que ainda persistem desigualdades significativas com relação à infraestrutura básica das escolas no espaço intraurbano de um município. $\mathrm{O}$ caso da rede federal de ensino demonstra ser uma exceção que merece registro.

Ao final, retomamos o argumento a favor de políticas de correção das desigualdades a partir do princípio da equalização e do olhar espacial para o caso dos grandes centros urbanos brasileiros. 


\section{Sobreposição de Desvantagens e Reprodução das Desigualdades}

Ao final do século XIX, como consequência da Revolução Industrial, a necessidade de uma mão de obra minimamente escolarizada passa a entrar na agenda dos países industrializados, porém combinada a uma visão ou a um sentido civilizatório e de ordem social a ser promovido via educação pública. Com isso, o ideal de promover a massificação da educação vai ganhando força, pioneiramente, nos EUA e, em sequência, entre os países em processo de industrialização da Europa Ocidental (COLEMAN, 2011). De modo mais claro, as primeiras escolas públicas surgiram com a ideia de uma escola para todos, objetivando democratizar o ensino e o acesso à educação "formal", antes privilégio das classes mais abastadas. Assim, a escola passa a ser vista como ambiente de redução das desigualdades de oportunidade, na perspectiva de uma sociedade liberal. Há, dessa maneira, dois movimentos ou visões sobre a educação não necessariamente contraditórias entre si: atendimento das demandas do capitalismo industrial e meio de ascensão social.

Para Bourdieu e Passeron (1982), porém, essa promessa parte de uma premissa equivocada: a de que alunos de diferentes origens sociais teriam a mesma probabilidade de ascender socialmente, o que não seria verdade, pois alunos de diferentes origens possuem diferentes níveis de capital cultural e esse seria essencial para o desempenho acadêmico e, ao fim, para a reprodução das hierarquias sociais existentes. Sendo uma estrutura simbólica, a cultura dominante seria a da classe dominante, vista, por isso mesmo, como a mais importante e legitimando a escola como responsável por transmitir essa cultura aos alunos (CUNHA, 2008). Para essa vertente, a escola e o sistema escolar não promoveriam o ideal da igualdade de oportunidade; ao contrário, criaria seus próprios mecanismos de reprodução das hierarquias sociais existentes.

Esse debate acaba por criar um consenso de que a existência e o acesso à escola não são suficientes para promover a igualdade de oportunidades. Como marco desse consenso, o Relatório Coleman, produzido em 1966 como encomenda do governo norte-americano, mostra que a distribuição de condições educacionais nos EUA à época era extremamente desigual e com forte segregação espacial e racial. Os principais resultados do relatório demonstram que alunos negros têm acesso à escola de pior qualidade em comparação com alunos brancos e que alunos pobres possuem dificuldades de acesso à escola, com pior qualidade quanto ao currículo oferecido e à infraestrutura das escolas.

Os fatores que funcionam como impedimento para que a igualdade de oportunidades seja atingida estão fortemente imbricados, gerando dificuldade de compreender isoladamente suas causas. Durlauf (2001), a partir de um olhar microssociológico, lista dois mecanismos causais que explicariam as diferenças entre jovens (ou alunos) de periferias e de áreas mais centrais/ricas: o peer group effect - ou a influência de amigos e conhecidos -; e o role model effect - os modos de vida de adultos como referenciais ou modelos de escolha de vida para os mais jovens.

Segue disso o entendimento de que não é possível depositar apenas na política educacional a expectativa de melhorias das condições de aprendizagem e de superação das desigualdades. De fato, apesar das evidências bem-documentadas dos efeitos de fatores externos à escola no desempenho escolar (ALVES; SOARES, 2013), o debate público sobre esse problema no Brasil ainda se restringe à análise crua dos indicadores, sem levar em conta o perfil socioeconômico dos novos alunos que ingressaram na escola em tempo recente, pertencentes aos segmentos historicamente mais vulneráveis da população brasileira. Se as condições sociais de origem afetam o desempenho escolar, então parte dos resultados aquém do desejável nos indicadores educacionais brasileiros é explicada pela recente integração à escola de camadas tradicionalmente excluídas, como a população do campo, os negros e os muito pobres.

Por outro lado, há estudos que contestam a ideia de que a escola não possa fazer a diferença e mostram que fatores intraescolares ou de gestão de sistemas de ensino podem aumentar ou atenuar a 
reprodução das desigualdades sociais (DUBET et al., 2012; PAYNE; ORTIZ, 2017). Dubet, Durru-Bellat e Vérétout (2012) identificam que escolas que adotam estratégias pedagógicas mais individualizadas parecem conseguir alterar as fortes estruturas de reprodução das desigualdades existentes e aumentar o desempenho escolar do alunado.

O caso do estado do Ceará, no Brasil, tem sido utilizado como exemplo de uma gestão pública que pode transformar o resultado educacional mesmo em condições de alta prevalência de condições socioeconômicas adversas (BONAMINO et al., 2019). O estado tem conseguido elevar o desempenho das escolas no Índice de Desenvolvimento da Educação Básica (IDEB), superando estados com maior capacidade de gasto por aluno e menor proporção de alunos em situação de pobreza, o que reforça o entendimento de que é possível encontrar soluções para a superação das condições exógenas à escola que impactem o desempenho escolar.

De fato, alguns estudos mostram que iniciativas e ações de escolas e sistemas de ensino podem tanto adotar estratégias que rompem com os mecanismos reprodutores das desigualdades sociais de origem quanto reproduzi-los. O estudo de Oliveira e Carvalho (2017) sobre uma política de combate à distorção idade-série em uma escola mostra que gestores escolares pré-classificam alunos que são "merecedores" de apoio extra para superar suas dificuldades de aprendizagem daqueles que "não se esforçam" para estudar ou que "não querem nada". Esses critérios acabam por determinar o acesso e o apoio que serão recebidos por alunos nas classes de aceleração, os quais tendem a ser, justamente, o alunado mais pobre, em famílias de baixa renda e com pais de baixíssima escolaridade. Como discute a literatura conhecida como "burocracia de nível de rua" (LIPSKY, 1980; LOTTA; SANTIAGO, 2017), essa discricionariedade de burocratas que trabalham na "ponta do sistema" (i. e., diretamente com o cidadão que recebe o serviço, tomando decisões cotidianas em suas rotinas de trabalho) pode afetar quem terá acesso a que tipo de serviço e, potencialmente, alterar a própria lógica de direitos contida no desenho institucional da política no momento de sua formulação.

Girotto e Cássio (2018), por exemplo, verificam que as estratégias e decisões sobre a implementação de escolas em tempo integral na rede estadual de São Paulo acabaram por "expulsar" alunos advindos de famílias em situação de maior vulnerabilidade social, criando, assim, "ilhas de excelência”, que aumentam as desigualdades educacionais. Em outras palavras, esse é outro resultado que ilustra como políticas e ações educacionais podem, na verdade, reproduzir as desigualdades sociais existentes.

Partindo da premissa de que seria possível a escola interferir em determinados mecanismos de reprodução da pobreza e das desigualdades sociais, alguns autores vão argumentar que há um leque de ações de planejamento e gestão de políticas educacionais que poderiam ser instrumentos efetivos para a correção de desigualdades educacionais. Alves e Soares (2013) notam que a infraestrutura nas escolas medida como a presença de laboratórios de informática e de ciências, biblioteca etc. - está associada a um melhor desempenho no IDEB, ainda que com maior peso nas séries iniciais do Ensino Fundamental. Padrões desiguais de condições de infraestrutura em escolas públicas foram também observados para o caso da Região Metropolitana do Recife por Bezerra (2017), com viés de maior precariedade em escolas mais afastadas e de maior concentração de população em situação de alta vulnerabilidade social. Esses dois resultados sugerem que a escola e a gestão educacional - um fator explicativo interno - afetam o desempenho de alunos em algumas circunstâncias.

Com efeito, há poucos estudos sobre os critérios de alocação de recursos, humanos e materiais, utilizados por gestores de secretarias municipais e estaduais de educação, bem como sobre a adoção ou não de estratégias de equalização ou correção de desigualdades. Torres et al. (2010) mostram que a adoção de regras abstratas e universais para a alocação de professores em escolas da rede pública acaba por gerar fortes incentivos para que profissionais mais qualificados e com mais anos de experiência optem, sistematicamente, por atuar em escolas mais centrais. O resultado é que escolas localizadas na periferia dos centros urbanos 
e com maior concentração de um alunado em condições de alta vulnerabilidade social são justamente as que mais recebem professores temporários, em início de carreira ou com baixa pontuação no concurso de ingresso à carreira. Apesar de existirem pagamentos adicionais para incentivar professores a trabalhar em escolas de "difícil acesso”, esses não são suficientes para alterar o padrão desigual de distribuição de professores na rede de ensino.

Partindo da premissa de que a educação pode promover uma efetiva igualdade de oportunidades, a situação é a oposta ao desejável: são justamente as escolas que atendem alunos de maior vulnerabilidade social, com sobreposição de desvantagens, as que mais se beneficiariam de uma educação com profissionais mais qualificados e experientes. Ribeiro et al. (2016) revisam estudos que apontam os efeitos da segregação residencial nas desigualdades educacionais. Em um dos resultados, os autores identificam, na cidade do Rio de Janeiro, maior prevalência de crianças fora da escola em locais de alta concentração de adultos com inserção precária no mercado de trabalho, mesmo após a adoção de controles estatísticos de aferição de outras variáveis explicativas.

De modo similar, Torres, Ferreira e Gomes (2005) estimam os efeitos de residir em áreas periféricas do município de São Paulo nas chances de jovens de 18 e 19 anos finalizarem o Ensino Médio. Ainda que as variáveis tradicionais, como renda, sexo e cor/raça, permaneçam o principal fator explicativo, os efeitos da residência em locais de alta concentração de pobreza têm também uma contribuição explicativa. Os autores argumentam que tais resultados apontam a necessidade de um olhar mais complexo da gestão educacional, em que as condições espaciais sejam incorporadas às agendas governamentais de modo a relativizar a adoção padronizada, universalista e simplista como critério único para a tomada de decisão.

Dito de outro modo, iniciativas com foco prioritário na correção de desigualdades não parecem fazer parte da agenda de políticas de educação. Parte do problema da reprodução das desigualdades e da promoção do ideário de igualdades de oportunidades, porém, passa, necessariamente, pelo conhecimento das localidades e de suas características constitutivas. Na próxima seção, apresentamos uma aplicação empírica que almeja ilustrar essa discussão.

\section{Aplicação Empírica para um Olhar Espacial na Gestão Educacional}

A possibilidade de correção de desigualdades sociais de origem pela educação deve ser um ato deliberado da gestão educacional. A partir de dados empíricos selecionados, nesta seção, procuramos demonstrar como o olhar espacial para a equidade pode ser apropriado pela gestão pública como forma de planejamento e formulação de políticas e serviços educacionais. Uma vez que nosso argumento é que o fator espacial deve ser considerado durante o planejamento de ações e metas, o primeiro passo nessa estratégia é conhecer o histórico de ocupação dos espaços por diferentes grupos sociais.

De maneira breve, utilizamos o caso da cidade de Natal, mostrando como se constituíram os espaços segregados que, como consequência, terão perfis de alunado muito distintos.

\section{Caracterização Socioespacial dos Bairros de Natal}

O principal marco temporal de urbanização intensa de Natal é a |Segunda Guerra Mundial, dado que a cidade, por sua localização estratégica, foi escolhida como base para militares norte-americanos e brasileiros (SILVA, 2006; CLEMENTINO, 1990). A ausência de condições urbanas mínimas resultou em problemas de abastecimento e acesso a serviços básicos, o que fez com que investimentos de infraestrutura urbana fossem realizados em Natal e Parnamirim, cidade vizinha, transformando a configuração espacial da cidade (CLEMENTINO, 1990; SECRETARIA..., 2016). 
Após a guerra - com a permanência de alguns militares e a chegada de servidores públicos, para atuar nos órgãos de estado, e de populações de outros estados e cidades -, surgem, nas décadas de 1950 e 1960, as primeiras políticas habitacionais, que também vão marcar a ocupação espacial da cidade. Conjuntos habitacionais e loteamentos vão se inserir próximos às áreas militares, nas Zonas hoje chamadas Sul e Leste (Fig. 1), de alta valorização imobiliária, e tornando-se elas locais de moradia das camadas média e alta da sociedade. Essa combinação de fatores gera um movimento de afastamento da população de baixo poder aquisitivo para áreas além do Rio Potengi, dando origem à mais marcante divisão socioespacial da cidade em suas dimensões geográfica e simbólica - entre as duas margens do rio -, a qual permanece no imaginário da população local até os dias de hoje como "o outro lado da ponte" ou "a Zona Norte" (CLEMENTINO, 1990, p. 190).

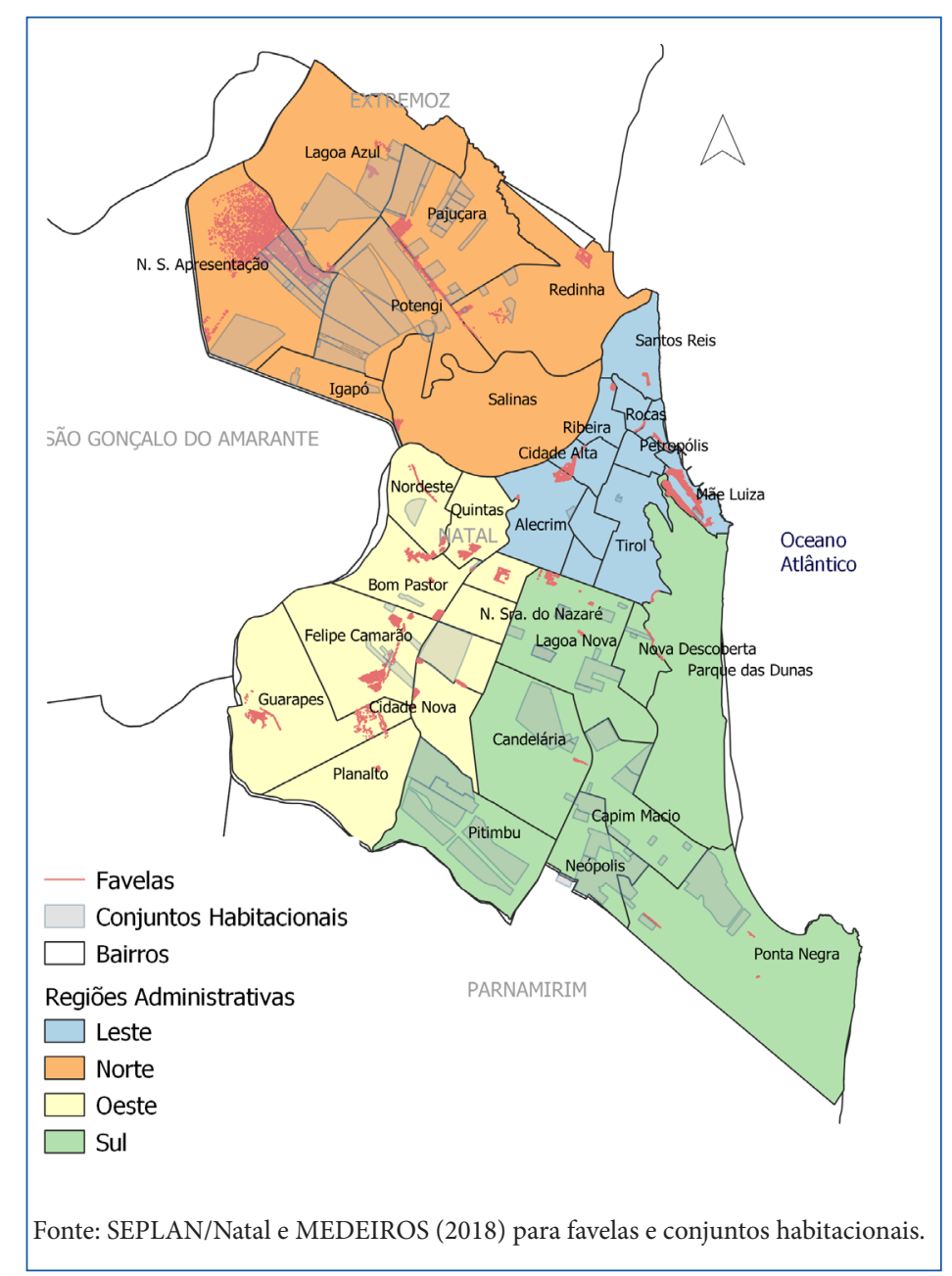

Figura 1. Bairros de Natal por região administrativa e localização de favelas e conjuntos habitacionais

De modo similar a outras cidades brasileiras, a atuação do poder público, por meio da construção de conjuntos habitacionais pela COHAB e a INOCOOP, durante as décadas de 1970 e 1980, foi decisiva para o aumento da segregação socioespacial da cidade (MEDEIROS, 2018). Nas Zonas Leste e, especialmente, Sul, o poder público atua com a construção de conjuntos para as camadas médias (MEDEIROS, 2018, p. 175). Já na Zona Norte, Silva (2006) e Medeiros (2018) identificam um número elevado de conjuntos habitacionais voltados para as classes populares, além de loteamentos irregulares e ilegais e áreas de favela (Fig. 1). 
No interior desse processo de ocupação da Zona Norte, Medeiros (2018) destaca que os conjuntos habitacionais tinham maior disponibilidade de espaços reservados para equipamentos e serviços públicos em comparação a áreas adjacentes - como nos loteamentos irregulares e ilegais e nas áreas de favelas -; ou seja, tinham a previsão de construção de escolas e outros prédios públicos (MEDEIROS, 2018). Como veremos, esse fato terá implicações para a construção de escolas a partir de meados da década de 1980, quando os governos locais iniciam políticas de expansão de acesso à escola.

Em breve síntese, a constituição histórica da ocupação urbana de Natal explica a distribuição dos grupos sociais na cidade e a segregação socioespacial que se observa atualmente. No presente, a cidade de Natal possui uma população estimada de 877.640 habitantes e é composta pelas Regiões Administrativas Norte, Sul, Leste e Oeste, divididas em 36 bairros (Fig. 1). Em termos de porte populacional, a Zona Norte é a maior de todas essas regiões, com 303.543 habitantes e o maior contingente de população em idade escolar. Em seguida, vem as Zona Oeste, Sul e Leste, de acordo com a Secretaria Municipal de Meio Ambiente e Urbanismo de Natal (2016). O bairro Salinas e a região do Parque das Dunas são áreas de proteção ambiental, praticamente inabitadas, e, portanto, não serão objeto de análise.

Como se pode observar na Fig. 2, há um claro padrão espacial de concentração de população de menor renda nas Zonas Norte e Oeste da cidade em comparação às Zonas Leste e Sul, ainda que a análise por bairros no interior de cada região administrativa revele também uma complexa diversidade no tecido social.

Na Zona Norte, destaca-se o bairro de Potengi, com renda mais alta em comparação aos demais bairros da região. Esse bairro recebeu um quantitativo significativo de conjuntos habitacionais com previsão de infraestrutura urbana e ordenamento territorial. Contudo, a diversidade de condições, mesmo no interior dessa região, é grande. No outro extremo, o bairro de Nossa Senhora da Apresentação (Fig. 1) concentra população de baixa renda e elevada presença de favelas, fruto de ocupações mais recentes. Algo similar ocorre na Zona Oeste da cidade, com o bairro Guarapes apresentando prevalência de pessoas de menor renda, também com maior presença de favelas comparativamente a bairros vizinhos. Por outro lado, há bairros também na região Oeste com populações em diferentes condições sociais, como aqueles que fazem divisa com bairros da Zona Sul, de renda mais alta. A Zona Leste, apesar do rendimento mais alto, no geral, também apresenta enclaves de alta vulnerabilidade social, como nos bairros de Rocas e Mãe Luiza. Por fim, a Zona Sul é a região da cidade de maior homogeneidade socioeconômica. Ainda assim, verificam-se núcleos de maior concentração de população de menor renda, como Neópolis e Ponta Negra.

Diante disso, pode-se sintetizar que:

1. As Zonas Norte e Oeste possuem maior concentração de população de baixa renda e maior presença de favelas e loteamentos irregulares ou ilegais, ao mesmo tempo que há enclaves territoriais com padrão de ordenamento urbano distinto como resultado das políticas habitacionais de construção de grandes conjuntos habitacionais para as classes média-baixa e operária;

2. A Zona Leste apresenta uma composição heterogênea, com bairros de maior presença de classes média e alta, e outros de elevada concentração de pobreza e favelas; e

3. AZona Sul tem maior homogeneidade socioeconômica e presença mais elevada de bairros de renda alta e média, com poucas áreas de favela em comparação com as demais regiões.

\section{A Possibilidade de um Olhar Equalizador das Oportunidades}

A partir do conhecimento da distribuição espacial dos grupos sociais, podemos aplicar princípios equalizadores para analisar as condições educacionais. De uma enormidade de indicadores disponíveis, 


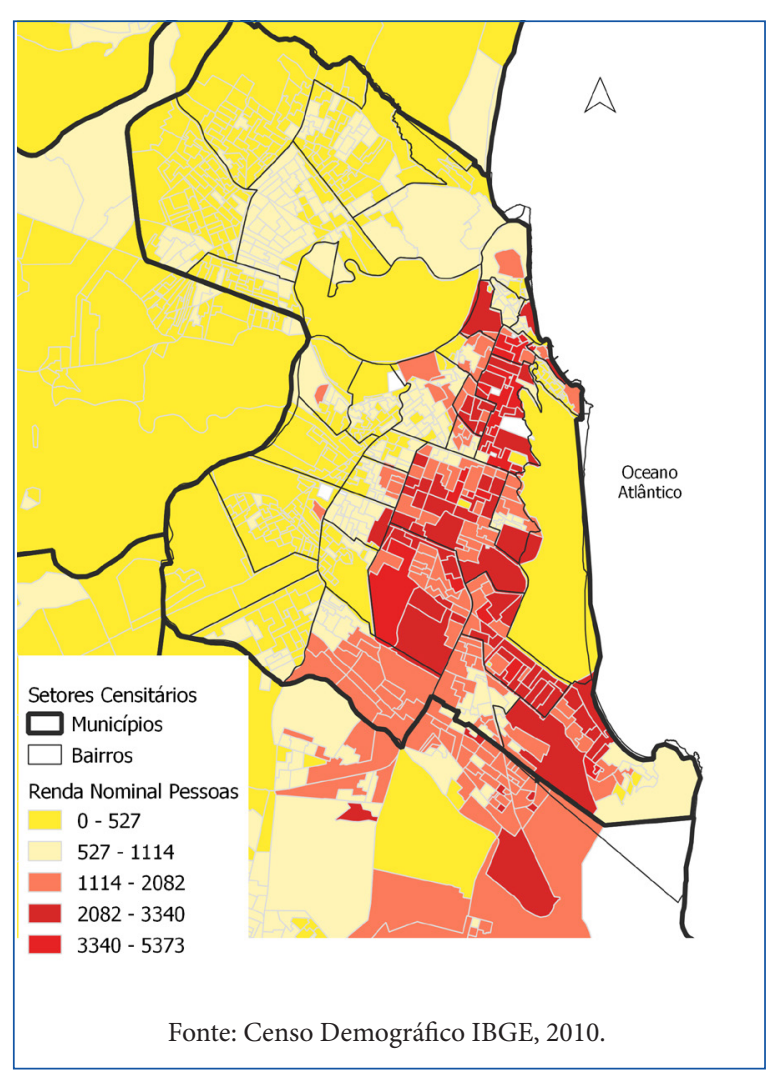

Figura 2. Rendimento nominal médio mensal das pessoas de 10 anos ou mais de idade (com e sem rendimento) em reais por setor censitário. Município de Natal (RN), 2010

escolhemos alguns para mostrar como análises simples podem produzir um diagnóstico inicial dos locais que combinam maior vulnerabilidade social com menor disponibilidade de recursos pedagógicos. A análise foca nas escolas estaduais e municipais de Natal, que atendem à vasta maioria do alunado. Algumas comparações pontuais com as escolas privadas e com a rede federal de ensino, porém, são também apresentadas. Os dados utilizados têm como fonte bancos de dados públicos disponibilizados pelo Ministério da Educação (MEC).

A Tabela 1 mostra o Índice de Nível Socioeconômico da Escola (INSE), calculado pelo Instituto Nacional de Estudos e Pesquisas Educacionais Anísio Teixeira (INEP/MEC). O indicador estima o nível socioeconômico dos alunos em cada escola e é uma medida mais precisa do perfil do alunado em comparação a estimativas baseadas na população residente no entorno das escolas. É calculado com base nos questionários respondidos pelos alunos no exame nacional do Sistema de Avaliação da Educação Básica (SAEB) e do Exame Nacional do Ensino Médio (ENEM), ambos de 2015, em todas as escolas participantes (públicas ou privadas). Sua composição inclui dimensões como renda familiar, posse de bens, contratação de serviços de empregados domésticos pela família dos estudantes e nível de escolaridade de seus pais ou responsáveis. $\mathrm{O}$ índice varia de 0 a 100 e é normalmente divulgado em grupos ou níveis, mas aqui optamos por utilizar os valores absolutos por escola.

Com relação aos valores médios no INSE, as escolas das redes municipal e estadual têm alta similaridade. Os alunos da rede federal de ensino (Instituto Federal do Rio Grande do Norte [IFRN]) têm perfil socioeconômico ligeiramente mais alto e próximo, na média, dos valores das escolas privadas. O campus central do IFRN, na Zona Leste da cidade, tem um alunado de maior condição socioeconômica $(52,7)$ em 
Tabela 1. Índice de nível socioeconômico da escola por dependência administrativa. Escolas de Ensino Fundamental e Médio do município de Natal (RN), 2015.

\begin{tabular}{cccccc}
\hline $\begin{array}{c}\text { Dependência } \\
\text { Administrativa }\end{array}$ & $\begin{array}{c}\text { Escolas } \\
(\mathbf{N})\end{array}$ & $\begin{array}{c}\text { INSE } \\
\text { Médio }\end{array}$ & $\begin{array}{c}\text { INSE } \\
\text { Mínimo }\end{array}$ & $\begin{array}{c}\text { INSE } \\
\text { Máximo }\end{array}$ & Desvio-padrão \\
\hline Municipal & 72 & 47,3 & 42,4 & 53,9 & 1,9 \\
\hline Estadual & 96 & 47,4 & 41,8 & 54,1 & 3,0 \\
\hline Federal & 2 & 51,1 & 49,6 & 52,7 & 2,2 \\
\hline Privada & 43 & 54,5 & 44,3 & 69,3 & 6,9 \\
\hline
\end{tabular}

Fonte: INEP/MEC com elaboração nossa.

comparação ao campus da Zona Norte $(49,6)$. É interessante notar que há variação significativa no interior de cada rede, ainda que menor nos casos das escolas municipais e estaduais. A maior variação está entre as escolas privadas: o valor mínimo das escolas privadas é próximo aos valores mínimos de escolas municipais e estaduais; porém o valor máximo está muito distante de todas as outras escolas do município. Isso mostra que nem todas as escolas privadas são de elite e algumas atendem alunos de perfil socioeconômico similar ao da escola pública. A percepção generalizada de má avaliação, especialmente dos pais, das escolas públicas pode explicar a oferta de escolas privadas atendendo alunos de perfil socioeconômico tão baixo ou menor que alunos da escola pública.

Como nosso foco de análise está na rede pública de ensino, vale explorar um pouco mais as escolas municipais e estaduais, que atendem a mais de $60 \%$ de todos os alunos dos Ensinos Fundamental e Médio na cidade. Como se observa na Tabela 1, apesar de uma média similar com relação ao indicador socioeconômico, há uma variação de situações no interior das redes municipal e estadual. Isso significa que há escolas que concentram um alunado que advém de famílias de baixa renda, pais de baixa escolaridade e menor posse de bens, sugerindo uma situação de acúmulo de desvantagens, como discutido na primeira seção deste texto, o que, de início, impacta o desempenho escolar.

Escolhemos dados sobre a existência de infraestrutura pedagógica nas escolas (biblioteca, laboratório de informática, laboratório de ciências e número de computadores disponíveis para uso dos alunos) e o INSE para as análises. Iniciamos com um olharglobal sobre as quatro regiões (zonas) administrativase, em seguida, para os bairros da cidade.

Como se observa a partir da Tabela 2, há padrões similares e distintos entre as regiões da cidade. Do ponto de vista do perfil socioeconômico dos alunos, as médias para todas as zonas são muito similares, ainda que ligeiramente menores nas Norte e Oeste, locais que, como vimos, concentram população de menor renda. Com relação ao número de computadores nas escolas que são para uso dos alunos - isto é, excluindo computadores para uso administrativo -, destaca-se uma média menor para as Zonas Norte e Leste. É interessante notar que esse indicador, nessas duas regiões, seria significativamente alterado se introduzíssemos as duas escolas da rede federal: a Zona Leste passaria de 10,2 para 27,5 e a Zona Norte, de 9,1 para 12,6. De fato, a infraestrutura dessas duas escolas é altamente diferenciada em comparação às escolas estaduais e municipais: no campus da Zona Norte, o número de computadores por aluno é de duzentos e na Zona Leste (campus central), de setecentos. Para fins de comparação, a escola estadual que tem o maior número de computadores para seus alunos arregimenta trinta máquinas. Com efeito, a decisão de construir um campus na Zona Norte da cidade (inaugurado em 2007) tem um impacto equalizador importante para essa região, ainda que muito limitado, dado o pequeno número de alunos atendidos, os quais não necessariamente são residentes daquela região e, como vimos, também não são os mais vulneráveis em termos socioeconômicos. 
Tabela 2. Indicadores selecionados para escolas de Ensino Fundamental e Médio das redes municipal e estadual por região administrativa. Município de Natal (RN), 2017.

\begin{tabular}{ccccccc}
$\begin{array}{c}\text { Região } \\
\text { Administrativa }\end{array}$ & $\begin{array}{c}\text { Escolas } \\
(\mathbf{N})\end{array}$ & $\begin{array}{c}\text { Média de } \\
\text { INSE }^{*}\end{array}$ & $\begin{array}{c}\text { Média de } \\
\text { Computador para } \\
\text { Uso de Alunos }\end{array}$ & $\begin{array}{c}\text { Escolas com } \\
\text { Biblioteca } \\
(\%)\end{array}$ & $\begin{array}{c}\text { Escolas com Lab. } \\
\text { Informática } \\
(\%)\end{array}$ & $\begin{array}{c}\text { Escolas com Lab. } \\
\text { Ciências } \\
(\%)\end{array}$ \\
\hline Leste & 40 & 47,4 & 10,2 & $90,0 \%$ & $82,5 \%$ & $27,5 \%$ \\
\hline Norte & 54 & 46,7 & 9,1 & $77,8 \%$ & $66,7 \%$ & $11,1 \%$ \\
\hline Oeste & 43 & 46,6 & 12,2 & $83,7 \%$ & $86,0 \%$ & $25,6 \%$ \\
\hline Sul & 34 & 49,6 & 12,9 & $79,4 \%$ & $76,5 \%$ & $41,2 \%$ \\
\hline
\end{tabular}

${ }^{*}$ Dados de 2015. Fonte: INEP/MEC e SEPLAN/Natal, com elaboração nossa.

Com relação a alguns indicadores de infraestrutura pedagógica nas escolas, observa-se um padrão de relativa homogeneidade no caso de existência de bibliotecas, ainda que seja surpreendente ainda encontrarmos escolas de Ensino Fundamental e Médio (portanto, excluem-se creches e pré-escolas) sem biblioteca - especialmente levando em consideração a existência de programas federais de apoio à instalação de bibliotecas desde, pelo menos, a década de 1990. Nesse caso, as Zonas Norte e Sul aparecem com percentuais menores comparativamente às outras regiões. Padrão similar ocorre com a disponibilidade de laboratórios de informática nas escolas, sendo que a Zona Norte apresenta o menor percentual de escolas equipadas. Esses dois indicadores parecem sugerir que algumas escolas têm dificuldade de acessar ações que apoiem a instalação de infraestrutura pedagógica, na medida em que o Governo Federal também dispõe de programas de financiamento de laboratórios de informática nas escolas públicas desde o final da década de 1990. Ainda que não tenhamos informações sobre quais são os critérios adotados pelas secretarias de educação para a alocação de recursos, parece evidente que critérios equalizadores (i.e., com prioridade nas regiões que concentram uma população de maior vulnerabilidade social) não são adotados de modo deliberado pelos gestores.

Por fim, a existência de laboratório de ciências é interessante por vários motivos. Primeiro, é um equipamento relativamente raro, estando presente em apenas $25,4 \%$ das escolas estaduais e municipais, sendo os valores ligeiramente mais altos nas escolas estaduais (dado não apresentado), possivelmente em associação à oferta de Ensino Médio por essa rede de ensino. Por ser equipamento incomum, observam-se mais claramente as desigualdades de acesso. A Zona Sul da cidade apresenta o maior percentual de escolas com laboratório de ciências (41,2\%), significativamente acima da média. No outro extremo, apenas 11\% das escolas públicas da Zona Norte têm acesso a esse tipo de equipamento. Isso parece sugerir que alguns gestores escolares conseguem acessar iniciativas para equipar suas escolas, enquanto outros, não. A menor oferta de iniciativas federais de apoio para instalação de laboratórios de ciências também revela a centralidade de programas federais para a equalização de disparidades de condições pedagógicas nas escolas públicas. Em outras palavras, quando estados e municípios são deixados, sozinhos, a cargo de equipar suas escolas, tende-se à produção ou ao aprofundamento das desigualdades existentes. Note-se também que as duas escolas federais (não listadas na Tabela 2) têm laboratório de ciências disponível para seu alunado, reforçando o diferencial de infraestrutura pedagógica dessas escolas.

Aprofundando a aplicação empírica, apresentamos um cartograma que ilustra a distribuição espacial dos laboratórios de ciências, agora com dados desagregados por bairros, para uma análise espacial mais detida. A Fig. 3 apresenta a proporção das escolas com laboratório de ciências, agregadas por bairros. 


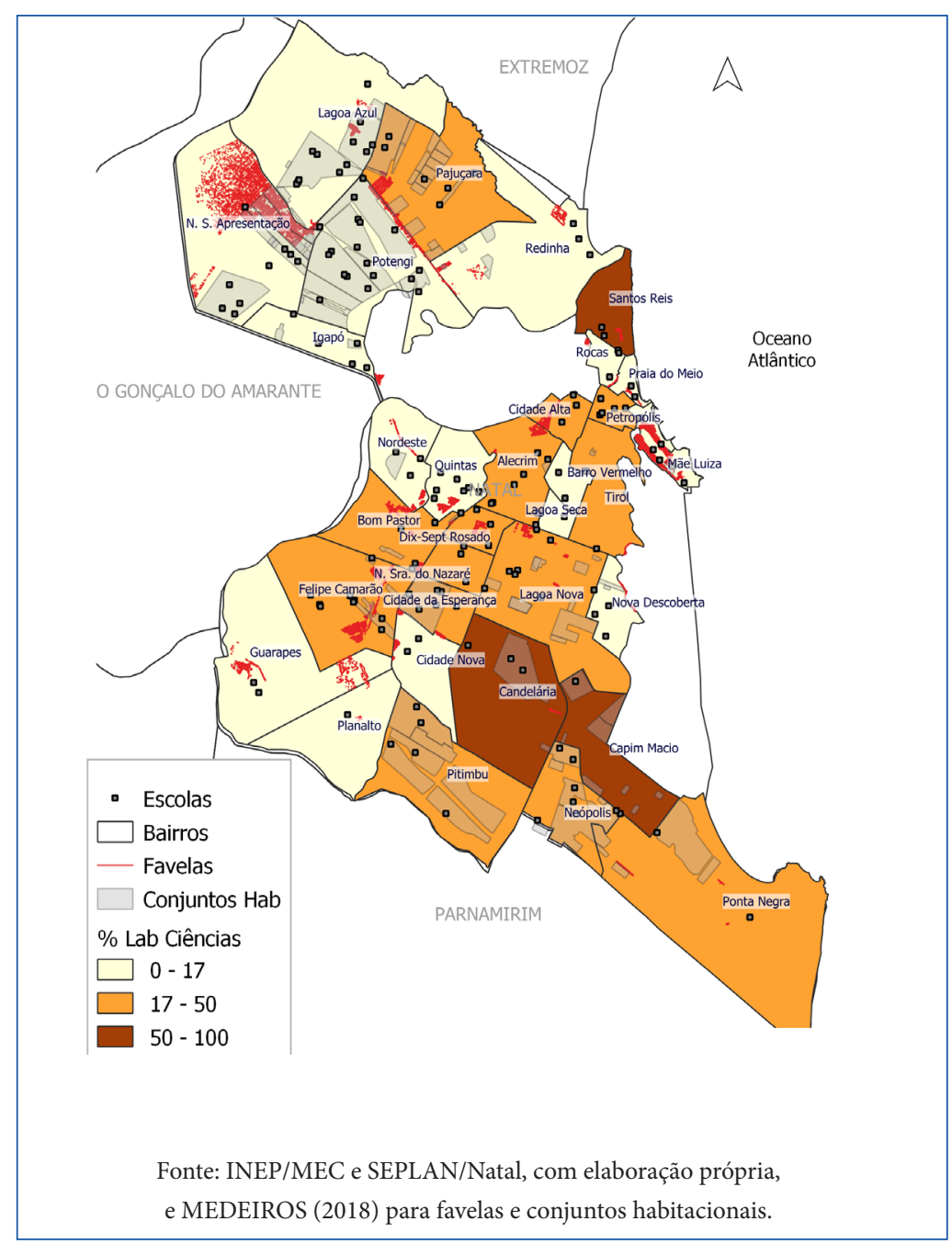

Figura 3. Proporção de escolas estaduais e municipais com laboratório de ciências por bairros. Município de Natal (RN), 2017

É notável que a Zona Norte apareça com a menor proporção desse equipamento. Como vimos, trata-se de uma região com lugares de alta concentração de um alunado de menor nível socioeconômico. Nos bairros de Redinha e Igapó, da Zona Norte, não há nenhuma escola com laboratório de ciências. Mesmo em Potengi, bairro com melhores condições socioeconômicas e de infraestrutura urbana nessa região, apenas $5 \%$ das escolas têm o equipamento. É nesse mesmo bairro que se localiza o campus Zona Norte do Instituto Federal, que dispõe desse tipo de laboratório, sugerindo a adoção de critérios socialmente equalizadores na construção desse equipamento na região. O único bairro que se destaca na Zona Norte é Pajuçara, com 33\% de escolas dispondo de laboratório de ciências, ligeiramente acima da média para todo o município.

Esse padrão também se repete em outros indicadores utilizados anteriormente - como laboratório de informática e número de computadores para alunos -, mas não serão discutidos aqui. Não temos explicações para isso, mas parece razoável assumir que os gestores responsáveis pelo planejamento da alocação de recursos nas escolas e redes não parecem adotar critérios de equalização levando em conta o perfil do alunado e as condições sociais em que se encontram. Dito de outro modo, os critérios de alocação de equipamentos pedagógicos parecem ser outros.

É interessante notar que outra região que concentra também população e alunado de menor renda, a Zona Oeste, apresenta melhor distribuição de laboratórios de ciências. É verdade que ainda se verificam 
desigualdades entre os bairros dessa região. Em três deles (Guarapes, Planalto e Nordeste) não existe nenhuma escola com esse tipo de equipamento, enquanto em outros dois (Cidade da Esperança e Bom Pastor), metade das escolas têm o equipamento - nesse caso, bem acima da média de $25 \%$ da cidade.

A região Leste tem uma situação similar à da região Oeste, porém com maior desigualdade em seu interior. Nos bairros de Mãe Luiza, Lagoa Seca, Rocas, Areia Preta e Barro Vermelho, não há escolas com laboratório de ciências. Muitos desses bairros concentram uma população em situação de alta vulnerabilidade social. No outro extremo, Santos Reis é um bairro em que 75\% das escolas públicas têm o equipamento.

Por fim, a Zona Sul é a que apresenta o maior percentual de escolas com laboratório de ciências. Como pode ser observado na Fig. 3, apenas um bairro destoa do padrão, Nova Descoberta, sem escolas com o equipamento. A média de acesso a esse tipo de equipamento na região Sul é a mais elevada do município: $41 \%$, com destaque para Capim Macio -bairro eminentemente de classe média-alta -, cuja única escola tem um laboratório de ciências para seus alunos.

Não sabemos que critérios são adotados para a distribuição dos equipamentos ou se essas solicitações dependem exclusivamente da iniciativa própria de gestores nas escolas (como diretores), mas claramente não há um critério distributivo que priorize as áreas e o alunado que mais se beneficiariam de melhorias na infraestrutura pedagógica das escolas - locais onde a escola é um dos principais mecanismos de superação das condições de pobreza e desigualdade. Para Girotto e Cássio (2018), esse padrão de reprodução das desigualdades é deliberado e não acidental; ou seja, seria resultado de decisões da própria administração pública, especialmente daquela baseada na nova gestão pública, na visão dos autores. Para outros, porém, essa mesma nova gestão pública explicaria o caso de sucesso verificado no crescimento de indicadores educacionais de modo equitativo em redes municipais do estado de Ceará a partir do papel deliberado e coordenador de ações do governo estadual em apoio aos municípios (SEGATTO, 2015; SUMIYA, 2015; BONAMINO et al., 2019).

É ainda possível especular que a questão das desigualdades no interior das redes de ensino e as estratégias de equalização ainda não tenham se tornado parte do debate público de modo suficiente para influenciar a agenda dos governos. Nesse sentido, é bastante salutar a inovação no novo Fundo de Manutenção e Desenvolvimento da Educação Básica e de Valorização dos Profissionais da Educação (FUNDEB) - Emenda Constitucional n. 108, de 2020 -, que induz (ou sugere) uma redistribuição no interior das redes de ensino, de modo a produzir maior equalização das escolas de uma mesma rede, ainda a ser definido em lei posterior.

\section{Considerações Finais}

De acordo com a revisão dos estudos apresentada neste texto, a escola pode ser tanto um efetivo mecanismo para a promoção da igualdade de oportunidades para seus alunos quanto, pelo contrário, reprodutora das desigualdades sociais de origem. Essa linha tênue que separa um papel do outro depende de um conjunto de fatores externos à escola, mas também das decisões de alocação de recursos e de outras iniciativas por parte de gestores da política educacional. Os estudos da área concluem que há sobreposição ou acúmulo de diferentes tipos de desvantagens para indivíduos em situação de vulnerabilidade social, acúmulos esses magnificados pelos padrões de segregação socioespacial típicos das cidades brasileiras. Em outros termos, residir em locais segregados, com alta concentração de pobreza, torna-se mais um elemento que favorece o acúmulo de desvantagens sociais.

Argumentamos que essas evidências mostram que a atuação do poder público nos locais de alta concentração de população em situação de vulnerabilidade social é ainda mais relevante no 
caso da educação, dado que essa tem o potencial de se constituir efetivo mecanismo de superação das condições sociais advindas da origem social. Para isso, a gestão da política educacional, seja em nível federal, estadual, distrital ou municipal, deve adotar um novo princípio orientador para a alocação de recursos e programas educacionais: um olhar espacial para a alocação de recursos pedagógicos e humanos, orientado pelo princípio da equalização (i. e., priorizando áreas de alta concentração de pobreza e vulnerabilidade).

Com base nos dados discutidos neste texto, concluímos que, mesmo entre escolas públicas no interior de uma mesma rede de ensino, ainda existem desigualdades no que se refere ao acesso a equipamentos pedagógicos considerados elementares e básicos. Mais do que isso, os dados apresentados parecem sugerir que os critérios de alocação de infraestrutura pelos gestores responsáveis pelas políticas educacionais não priorizam os locais de maior concentração de vulnerabilidade social.

Realizou-se aqui uma aplicação relativamente simples, passível de ser reproduzida por gestores e decisores de políticas ou programas educacionais. Outras unidades de análise, no nível de escolas ou, ainda, distinguindo por nível de ensino e tipo de rede (se estadual ou municipal), possivelmente iluminariam outros aspectos não observados aqui. Mesmo com essa limitação, acreditamos que a aplicação empírica permitiu ilustrar como gestores de políticas educacionais, seja nos municípios, seja nos estados, poderiam adotar um olhar espacial com o objetivo de equalizar as desiguais oportunidades entre o alunado, mesmo quando se consideram apenas as escolas públicas. Com uma perspectiva mais equalizadora, a escola pode almejar ações que rompam com a reprodução das desigualdades, ao adotar critérios de priorização do alunado em situação e em locais de alta concentração de vulnerabilidade social. É nesses locais e para essa população que a escola é um dos mais importantes mecanismos para a superação das desigualdades sociais de origem.

\section{Contribuição dos Autores}

Metodologia, Gomes S e Melo FYM; Problematização e Conceituação, Gomes S e Melo FYM; Análises e Redação, Gomes S e Melo FYM.

\section{Referências}

ALVES, M., T. G.; SOARES, J. F. Contexto escolar e indicadores educacionais: condições desiguais para a efetivação de uma política de avaliação educacional. Educação \& Pesquisa, São Paulo, v. 39, n. 1, p. 177-194, jan.-mar. 2013. https://doi.org/10.1590/S1517-97022013000100012

BEZERRA, R. M. Padrões espaciais de oferta de educação nos municípios: a região metropolitana de Recife. 2017. 122 f. Dissertação (Mestrado em Ciência Política) - Programa de Pós-graduação em Ciência Política, Universidade de São Paulo, São Paulo, 2017.

BONAMINO, A. et al. Arranjo Institucional de Implementação do PAIC e Burocratas de Médio Escalão. In: LOTTA, G. (org.). Teoria e análises sobre implementação de políticas públicas no Brasil. Brasília: Enap, 2019. p.193-223. 
BOURDIEU, P.; PASSERON, J. C. A reprodução: elementos para uma teoria do sistema de ensino. Trad. Reynaldo Bairão. Rio de Janeiro: Francisco Alves, 1982.

IBGE [INSTITUTO BRASILEIRO DE GEOGRAFIA E ESTATÍSTICA]. Características da população e dos domicílios: resultados do universo. Censo Demográfico 2010. Rio de Janeiro: IBGE, 2011.

CLEMENTINO, M. L. M. Complexidade de uma urbanização periférica. 1990. 302 f. Tese (Doutorado em Economia) - Instituto de Economia, Universidade Estadual de Campinas, Campinas, 1990.

COLEMAN, J. S. et al. Equality of Educational Opportunity. Washington: US Government Printing Office. 1966.

COLEMAN, J. S. O conceito de igualdade de oportunidades educacionais. Educação, Sociedade \& Culturas, Porto, v. 34, p.137-155, 2011. Disponível em: https://www.fpce.up.pt/ciie/revistaesc/ESC34/ ESC34_Arquivo_James.pdf. Acesso em: 12 fev. 2019.

CUNHA, M. A. A. O conceito “capital cultural” em Pierre Bourdieu e a herança etnográfica. Perspectiva, Florianópolis, v. 25, n. 2, p. 503-524, maio 2008. https://doi.org/10.5007/\%25x

DUBET, F; DURU-BELLAT, M.; VÉRÉTOUT, A. As desigualdades escolares antes e depois da escola: organização escolar e influência dos diplomas. Sociologias, Porto Alegre, n. 29, p. 22-70, abr. 2012. https:// doi.org/10.1590/S1517-45222012000100003

DURLAUF, S. The membership theory of poverty: the role of group affiliations in determining socioeconomic outcomes. In: DANZIGER, S. H.; HAVERMAN, R. H. Understanding poverty. New York: Russell Sage, 2001.

GIROTTO, E. D.; CÁSSIO, F. L. A desigualdade é a meta: implicações socioespaciais do Programa Ensino Integral na cidade de São Paulo. Arquivos Analíticos de Políticas Educativas, Tempe, v. 26, n. 109, p. 1-28, jul. 2018. https://doi.org/ 10.14507/epaa.26.3499

GOMES, S.; AMITRANO, C. Local de moradia na metrópole e vulnerabilidade ao (emprego e) desemprego. In: MARQUES, E. C.; TORRES, H. G. (orgs.). São Paulo: segregação, pobreza e desigualdades sociais, São Paulo: Senac, 2005.

GOMES, S.; SILVA, A. L. N.; COSTA, F. Governos partidários e políticas educacionais no Brasil do século XXI: a eficácia da democracia. In: ARRETCHE, M.; MARQUES, E.; FARIA, C. A. P. (orgs). As políticas da política: desigualdades e inclusão nos governos do PSDB e do PT. São Paulo: Editora Unesp, 2019.

LIPSKY, M. Street-level bureaucracy: dilemmas of the individual in public services. New York: Russel Sage Foundation, 1980.

LOTTA, G.; SANTIAGO, A. Autonomia e discricionariedade: matizando conceitos-chave para o estudo de burocracia. BIB, São Paulo, v. 83, n. 1, p. 21-42, 2017. Disponível em: https://www.anpocs.com/index. php/bib-pt/bib-83/11092-autonomia-e-discricionariedade-matizando-conceitos-chave-para-o-estadode-burocracia/file. Acesso em: 20 fev. 2019.

MARQUES, E. Redes sociais, segregação e pobreza. São Paulo: Editora Unesp, 2010.

MEDEIROS, S. R. F. Q. Segregação e gentrificação: os conjuntos habitacionais de Natal. Natal: EDUFRN, 2018. 
MENICUCCI, T. M. G.; GOMES, S. C. Políticas sociais: conceitos, trajetórias e a experiência brasileira. Rio de Janeiro: Fiocruz, 2018. (Temas em Saúde.)

OLIVEIRA, M. M.; CARVALHO, C. P. A implementação de uma política educacional de combate ao fracasso escolar: percepções e ações de agentes implementadores em uma escola municipal no Rio de Janeiro. Boletim de Análise Político-Institucional. Brasília: IPEA, n. 1, 2017.

PAYNE, C. M.; ORTIZ, C. M. Doing the impossible: the limits of schooling, the power of poverty. The Annals of the American Academy of Political and Social Science, Thousand Oaks, v. 673, n. 1, 2017. https://doi.org/10.1177/0002716217719019

RAGIN, C. The Comparative Method: moving beyond qualitative and quantitative strategies. Los Angeles/London: University of California Press, 1987.

RIBEIRO, L. C. Q. et al. Desafios urbanos à democratização do acesso às oportunidades educacionais nas metrópoles brasileiras. Educação \& Sociedade, Campinas, v. 37, n. 134, p. 171-193, jan.-mar. 2016. https://doi.org/10.1590/ES0101-73302016157093

SANTOS, M.; SILVEIRA, M. L. O Brasil: território e sociedade no início do século XXI. Rio de Janeiro: Record, 2006.

SECRETARIA MUNICIPAL DE MEIO AMBIENTE E URBANISMO DE NATAL. Anuário de Natal 2016. Natal: SEMURB, 2016. Disponível em: https://www.natal.rn.gov.br/bvn/publicacoes/anuario_2016. pdf. Acesso em: 15 de novembro de 2018.

SEGATTO, C. I. O papel dos governos estaduais nas políticas municipais de educação: uma análise dos modelos de cooperação intergovernamental. 2015. 196 f. Tese (Doutorado em Administração Pública e Governo) - Fundação Getúlio Vargas, São Paulo, 2015.

SILVA, A. F. C. Depois das fronteiras: a formação dos espaços de pobreza na periferia norte de Natal/ RN. 2006. 212 f. Dissertação (Mestrado em Arquitetura e Urbanismo) - Programa de Pós-graduação em Arquitetura e Urbanismo, Universidade Federal do Rio Grande do Norte, Natal, 2006.

SUMIYA, L. A. A hora da alfabetização: atores, ideias e instituições na construção do PAIC-CE. 2015. 243f. Tese (Doutorado em Políticas Públicas) - Programa de Pós-graduação em Administração, Universidade Federal do Rio Grande do Norte, Natal, 2015.

TORRES, H.; FERREIRA, M. P.; GOMES, S. Educação e segregação social: explorando o efeito das relações de vizinhança. In: MARQUES, E. C.; TORRES, H. G. (orgs.). São Paulo: segregação, pobreza e desigualdades sociais. São Paulo: Senac, 2005.

TORRES, H. et al. Educação na periferia de São Paulo: como pensar as desigualdades educacionais? In: RIBEIRO, L. C. Q.; KAZTMAN, R. (eds.). A cidade contra a escola: segregação urbana e desigualdades educacionais em grandes cidades da América Latina. Rio de Janeiro: Letra Capital, 2008.

TORRES, H. et al. Perfis do professorado da rede pública de São Paulo: a interação entre espaço, regras institucionais e escolhas individuais no resultado de uma política pública. Dados, Rio de Janeiro, v. 53, n. 1, p. 125-158, 2010. https://doi.org/10.1590/S0011-52582010000100005 


\section{Sobre as Autoras}

SANDRA GOMES é mestre e doutora em Ciência Política pela USP e Master of Arts pela Universidade de Londres, Reino Unido. Pós-doutorado no Centro de Estudos da Metrópole/CEBRAP. Áreas de pesquisa atuais: Processo decisório das políticas públicas; Gestão de políticas e programas; Federalismo e relações intergovernamentais.

FRANCYMONNI YASMIM MARQUES DE MELO é bacharela em Gestão de Políticas Públicas pela Universidade Federal do Rio Grande do Norte (UFRN) e mestra em Estudos Urbanos e Regionais pela mesma instituição. É pesquisadora colaboradora do projeto de pesquisa "Escolhas Políticas e Implementação de Políticas: Promoção da Equidade ou Reprodução das Desigualdades?”, vinculado ao Grupo de Pesquisa Estado e Políticas Públicas (DPP/UFRN).

Recebido: 18 fev. 2020

Aceito: 02 out. 2020 